\title{
Neo-pragmatism: an ethical anticipatory system
}

\author{
John Vodonick ${ }^{1}$ \\ Received: 15 February 2016 / Accepted: 10 August 2017 / Published online: 29 August 2017 \\ (C) The Author(s) 2017. This article is an open access publication
}

\begin{abstract}
In 1906 and 1907 William James delivered a series of lectures in Boston and New York. Those lectures later were distilled into a paper entitled PRAGMATISM A New Name for Some Old Ways of Thinking. In 1972 Robert Rosen began to develop the model that resulted in the publication of his breakthrough work Anticipatory Systems. Seven years later, with the publication of Philosophy and the Mirror of Nature Richard Rorty began to develop the interpretation of Pragmatism, which has come to be known as neoPragmatism. The theory of anticipatory systems as articulated by Robert Rosen argues that the activity of anticipation occurs through the encoding of models of the future and so, a deciduous tree will lose its leaves upon the shortening of daylightan environmentally neutral event-which is the precursor to winter. The tree anticipates (through the process of encoding its environmental cycle) the coming of winter and diverts sap, its lifeblood, underground to its roots and essentially hibernates during the cold time. Rosen shows that this quality of anticipation can be said to be the defining element of all life. Ethics are models that encode our values and operate upon the contingencies of the past in the adjudicatory function or the possible contingencies of the future in the heuristic function. Of all the mainstream ethical models pragmatism is the only approach that expressly acknowledges that the results of our decisions may either conflict with or harmonize with our values. The form of pragmatism known as neo-pragmatism looks to the communicative justification of our past or future actions in relationship to our values to determine whether they
\end{abstract}

John Vodonick

jvodonick@gmail.com

1 Marylhurst University, 11464 Willow Valley Rd., Nevada City, CA 95959, USA are good or bad. In this sense neo-pragmatism constitutes moral anticipation, as much encoded in human society as the dropping of leaves is encoded in a deciduous tree.

Keywords Ethics · Pragmatism · Neo-pragmatism · Anticipation $\cdot$ Richard Rorty $\cdot$ Robert Rosen

"What ought we to do now" Rosen (Hutchins, in [27: 370]):

I have always remarked, that the author proceeds for some time in the ordinary way of reasoning, and establishes the being of a God, or makes observations concerning human affairs; when of a sudden I am surprised to find, that instead of the usual copulations of propositions, is, and is not, I meet with no proposition that is not connected with an ought, or an ought not. This change is imperceptible; but is, however, of the last consequence. For as this ought, or ought not, expresses some new relation or affirmation, it is necessary that it should be observed and explained; and at the same time that a reason should be given, for what seems altogether inconceivable, how this new relation can be a deduction from others, which are entirely different from it [13].

\section{Introduction}

In J. M. Coetzee's novel Waiting for the Barbarians (1980) the Magistrate of a small town on the outskirts of civilization invites a representative of the Empire into his town and thereby opens the door to hell. The Magistrate is a good man who sees it as his ethical duty to welcome a stranger to his town and to be helpful to the stranger in accomplishing his mission. In 
so doing this good man becomes a party to murder, torture, and genocide. This is the ethical dilemma: how can we act ethically in the moment and be purblind to the evil that we unleash at the same time? Gregory Bateson identifies this dilemma as a double bind: to do good the Magistrate must accommodate evil.

Ethics is similar to the two-faced Janus; one face looks backwards and adjudicates our actions, utterances, and thoughts and the other face predicts what we will do in the future. The face that looks towards the past is embedded in "history" as a cultural or personal narrative. The face that is predictive in nature looks to what can be imagined. Both environments are contextual, the past a retrospective narrative, the future an imagined narrative.

In this paper I argue that the predictive element of ethics is only related to the adjudicative element in the sense that we adjudicate and predict through language. More to the point we justify our prediction of the outcome of our present utterances and actions through language. That being the case, the problem of Hume's guillotine (the "is-ought" problem) that has bedeviled ethical theorists for centuries evaporates. We are free to say: this is the condition that we have been in, and this is the condition that we predict to be our future. The ethical system that has been called "neo-pragmatism" is an anticipatory system that is ethical in nature in that it allows us to make predictions about how we will probably act in the future. Since the fundamental nature of neo-pragmatism is the justification of our utterances and our past or proposed actions to a contingent world we can resolve the problem of the double bind and find a solution to Hume's is/ought question.

\section{Ethics as an aspect of futures studies}

To the extent that Futures Studies is not concerned with human agency the notion of ethics is simply irrelevant; and this paper does not explore non-human agency future studies. Stated another way this paper is concerned with futures influenced by what Bell calls "preferrability" [1]; that is, future states that for identifiable and articulable reasons are considered to be preferable over other states. That being said those that discuss the relationship between ethics and Futures Studies concern foresighting. Masini points out that the grounding of Futures Studies, or foresighting has become linked to a philosophical basis and philosophic principles to guide the making of choices, but this view is not adequate [17]. Choices concerning a preferable future should be based upon what is "best" and not what will merely benefit a particular individual or group. Poli (2011) says that at least three applications of ethics exist in relation to Futures Studies: (a) as a deontological (Kantian) discipline governing the relationship of the futurist and her client; (b) as values that are a given within a particular futurist exercise; and (c) as the dynamic decision system between the agent and the future (as distinguished from the past). The primary interest in the relationship between ethics and Futures Studies is the set of values that anchor a particular forecasting exercise. This last category of Futures Studies is of interest here. Davis and Pyper argue that Actor Network Theory (ANT) is a useful model for scenario analysis that answers some of the shortcomings of Intuitive Logics methodology (IL) by focusing on the liberatory potential of possible futures rather than issues of power and legitimacy [6]. Rather than relying upon theory considered as "true," ANT explores the relationship between human and non-human actors (including modes of thought, memes, and technology) to seek out complex patterns of causality and discover emerging phenomena and structures of power. Waelbers and Dorstewitz point out that ANT modeling does not recognize human values or ethical systems as part of the decision- making process and suggest instead the classical pragmatic instrumentalism of John Dewey, which rejects any form of moral universalism while demanding an articulated moral position [28]. An ethical position applies to the agents' decision-making process since in any real-world scenario an ethical position is at play every time a decision is taken.

\section{A short ethical primer}

Ethics is fundamentally the systemization of knowledge bearing on good and bad conduct. Bell exhaustively surveys the field of ethics as applied to Futures Studies [1]; a complete discussion of all the strands of ethical thought is obviously beyond the scope of this paper, but to summarize, there are three major theories of contemporary normative ethics: (a) deontological ethics (based upon rules governing actions), (b) consequential ethics (emphasizing the consequences of actions), and (c) virtue ethics (emphasizing the effect of actions upon the moral character of the actor) [12]. These three branches are theories of ethics (ideas of the good and bad) in the sense that they are abstracted from a particular use in the exploration of the good and the bad. In this sense deontology, consequentialism, and virtue ethics are epistemological in nature; they all attempt to address the question of how we know what is good and what is bad prior to action.

From a deontological standpoint the actor knows that her actions are good or bad by making reference to a rule or rules. As May points out deontological ethics are not concerned with the consequences of taking action in accordance with set rules; good and bad are only referent to following the rules. Actions that have good consequences are bad if those actions violate a rule; for example, appropriating private property is generally considered to be morally wrong even though the property that is appropriated is food for starving children.

To the consequentialist it is only the effects of actions that make the actions good or bad. Consequentialist decisionmaking is a forward-looking process: the actor considers the 
likely consequences of her actions and then chooses the action that will have a good result. For example, a local government concerned with the amount of pollutants in the air might designate alternate no-drive days based upon the odd or even numbering of the license plate as a way to decrease the number of vehicles on the road, and thereby decreasing the level of emissions (as was done in Mexico City). However, when this regulation was adopted in Mexico City, many drivers bought a second used vehicle with a license plate number opposite that of their current vehicle. The older vehicles polluted more than the newer vehicles and as a result of the no-drive policy the level of air pollution in Mexico City increased dramatically. Regulating the days that an automobile can be driven logically would result in a good consequence, the reduction of exhaust pollutants; but in practice the fact that drivers avoid the regulation by purchasing a second older vehicle with a different license number resulted in an undesirable consequence, a net increase of exhaust emissions. A consequential analysis of the ethical question relies on a series of assumptions that are not necessarily accurate and accordingly cannot be said to be robust.

If one practices virtue ethics the actor engages in actions that are virtuous in and of themselves in that they are motivated by a virtuous trait, such as benevolence [5]. Accordingly an action is virtuous if performed by a virtuous person. A person is virtuous if she acts from a wellentrenched character trait that can be considered as virtuous (such as honesty or benevolence). Faced with a condition that requires a decision to be made based on the perception that a person or persons has an immediate need, the virtuous person acting from benevolence will attempt to fill that need (such as providing support to low income families with children). Ironically, as Folbre and Wolf argue, this well-motivated act can lead to serious fertility decline, ultimately undermining the welfare state itself [10].

\section{Anticipatory systems}

The nature of anticipatory systems as discussed in this paper is based upon the work of the mathematical biologist Robert Rosen [26]. Rosen and those carrying on his work have persuasively argued that every system that can be categorized as living has within itself a predictive model of itself and its environment. Those predictions about the future can be used as a control device in the present. Rosen defined an anticipatory system as:

"A natural system that contains an internal predictive model of itself and of its environment, which allows it to change state at an instant in accord with the model's predictions pertaining to a later instant" (as cited in [15]).
For example a deciduous tree contains an internal predictive model of the future and accordingly when days become shorter it will shed its leaves in anticipation of harsh weather conditions that occur in winter. The environmental event that caused the tree's leaves to drop is the shortening of the daylight sun, an essentially benign phenomenon. The anticipation is that harsh weather will follow and dropping leaves will allow the tree to shed that part of their systems (the leaves) that are most sensitive to cold or dry conditions. Thus the present change of state of the system (the tree and its relationship with its leaves) depends upon a future contingency.

Similarly, Rosen's notion of anticipatory systems is applicable to human systems $[25,26]$; he explains that the human immune system is an anticipatory system that uses the predictive model of infection growing in the body in a future state to marshal the body's defenses in the present for the purposes of engaging that future state. The Rosen formulation of an anticipatory (predictive) system is opposite to those theories and models of living systems that have generally prevailed. Those systems Rosen has called "reactive" in the sense that the system itself does not cause its present state to change in anticipation of the future, but instead causes its present state to change in reaction to events occurring in the present or the past. Rosen argues that this is so because any reactive system can be shown to simulate the behavior associated with an anticipatory system. Indeed there are certain systems that are only reactive in their nature; such systems can be said to be error based because when the system does not bring about the desired result it becomes subject to correction. In the language of systems thought it is subject to a negative feedback loop; if the system is operating as expected it may be subject to a positive feedback loop.

Contrasting the feedback loop is the feedforward loop, which Swan illustrates with the simple activity of an automatic watering system based upon the anticipation that the next day the lawn would be dry if it were not watered [27]. In a reactive system a dry lawn would be watered; in an anticipatory system the lawn is automatically watered because it would become dry if it were not.

Rosen was a pioneer and as is generally the case with all those who break new ground his work has engendered fierce controversy $[3,4,15,29]$.

\section{Feedback (reactive systems) and feedforward (anticipatory systems) as applied to ethics}

As discussed previously there are two aspects of ethics; the adjudicative aspect and the predictive aspect. In its adjudicative aspect any ethical system is a feedback loop: feedback is deemed negative when one's utterances or actions are not considered to be socially normative, or deemed positive when they are. In the extreme of this situation one might end up 
prison, whereas in the other case one might be promoted to a leadership role or held up as a positive model. The feedback function of any ethical system then is the adjudicative function. That function is usually (but not always) based upon a deontological system, and accordingly formal definitions of the good and the bad are used to adjudicate our utterances or our actions.

The remaining question raised by any consideration of ethics is what will we say or do in the future. At some point we will say or do something that will be subject to adjudication; however, this fact does not necessarily mean that we can predict our future actions by applying the same ethical approach as that applied by the adjudicatory function of any ethical system. Indeed the fact that an adjudicatory system exists establishes that the anticipatory aspect of ethics is separate and distinct from the adjudicative function. Why else do we create and administer socially adjudicative systems if the predictive function of an ethical system is congruent with the adjudicative function? The predictive function informs what we will do; the adjudicative function informs whether what we did was normative. What we will do and what we have done are not always the same.

\section{The pragmatic turn}

Pragmatism has its origins in the nineteenth century thought of James, Pierce, Dewey, and Mead and the idea that the true function of philosophy is to enable us to act effectively [11, $14,21,29]$. The core notion of early pragmatic thought is that all ideas, utterances, and actions can only be judged in relationship to our practices and the outcome of those ideas, utterances, and actions. This is contrasted to other ethical systems that are rule based (deontology), the effect upon the development of character (virtue), or the end result of our actions in an overall sense (consequentialist), none of which are concerned with the relationship that exists between our ideas, utterances, and actions and our practices (our values) over time. Pragmatism itself is not a methodology of adjudication or prediction. It is a methodology of identifying the results of ideas, utterances, and actions; it is a theory of meaning in that it attempts to clarify our thought. It is a theory of truth obtained by measuring the results of our thoughts against our practices and values and determining whether those results equated with our predictions.

\section{The linguistic turn and neo-pragmatism (the pragmatism of Richard Rorty)}

The late twentieth century saw a resurgence of interest in Pragmatism. The two primary manifestations of the revival in Pragmatism are a focus on the linguistic construction of philosophy, the linguistic turn; and a focus upon the contingent nature of our condition. As Dickstein (1998) comments:

From this viewpoint, statements about the world or judgments of value are always provisional; constructions of language that belong to a particular context. Such arguments, like similar ones in legal interpretation, have drawn outrage from critics upholding a more stable or objective view of linguistic meaning and literary judgment [8: 15].

The linguistic nature of late twentieth century pragmatism can be best described as a refocus from the consideration of the results of utterances or acts to the justification of utterances or acts. The difference is subtle, but profound. Classical Pragmatism was primarily concerned with clarifying a hypothesis by testing the practical results of the work. The original inquiry has matured in the late twentieth century to an inquiry into the practical aspects of our utterances and actions, more to the point of the linguistic justification of our utterances and actions in an environment in constant change. The NeoPragmatist view of the contingent nature of existence is core to understanding a deep suspicion of any statement that claims to be "true." From the pragmatist viewpoint our past or future acts are justified by our individual and collective values in relationship to the physical and social environments that we exist in. Neo-Pragmatic thought is not concerned with ontology or foundations; indeed, from the viewpoint of NeoPragmatism, ontology is a notion that ought to have historical interest only, and foundations are unprivileged notions that can only be used to justify one action, at one time, to one audience.

In summary we can say that Neo-Pragmatic ethics is the process of predicting our future conduct within a system that is contingent and without ontological foundation.

Rorty's thought [22-24] (much like Rosen's) has been met with great controversy: "If one is known by the enemies one makes, then Richard Rorty is, indeed, a well-known man" Brandom, R. B. (2000) [2: xiv]. Rorty was a prolific thinker and writer; his views are global and controversy has surrounded all of his positions. Of particular relevance to the topic of this paper is his view that normative standards of speech and conduct are based within the specific community that the actor exists in. In other words, there are no universal a priori standards, only those defined by the boundary critique of the community to which the actor belongs [7, 23, 24]. The charge of relativism is that most often leveled against Rorty, and the one that engenders the most controversy [20]. Edmonds also defended Rosen against the charge of relativism [9].

\section{Context, contingency, and relativism}

As noted, both Rorty (directly) and Rosen (indirectly) have been accused of "relativism" in the pejorative sense. Rorty 
defines relativism as "the belief that every view upon a certain topic, or perhaps about any topic, is as good as every other" [23: 166]. In terms of modeling processes Edmonds explains context as the set of factors that define the scope of a specific model [9]. When a group of models can be clustered so that their scopes are similar a "context" of the group may exist. For the Neo-Pragmatism of Rorty all understanding of any statement of "truth" is necessarily made from within and with reference to a specific context. Said another way, all statements about "truth" are made to be understood by a specific audience at a specific time and under specific circumstances; that is a "context." All statements purporting to be "the truth" are made through language or through some other medium of communication. It necessarily follows that statements dealing with the question of "what is to be done" are also contextual statements. This is the genesis of the accusation of Rorty's relativism.

Rosen argued that the distinction between simple and complex systems is substantial including full predictability on the part of simple systems and unpredictability on the part of complex systems; simple systems have no closed loops of entailment while complex systems do [25, 26]. These sharp distinctions together with others drew Rosen to challenge the tacit assumption of reductionism and universalism drawing the inference of relativism.

Neither the work of Rosen nor the thought of Rorty is reductionist; rather they are both context dependent. Rosen's theory of anticipation is based upon the context of complex systems in relationship to the environment the living system exists in. Rorty's notion of pragmatism is also context dependent since it expressly recognizes that statements or actions can only be justified (and not expressed as a universal truth) within the context of audience, time, and situation. Both the notion of anticipation as articulated by Rosen and Pragmatism and developed by Rorty are self-entailing, closed systems.

\section{The trolley simulation}

The Trolley Simulation is a classic test used to simulate the dimensions of an ethical system. It is a useful tool to compare and contrast outcomes under differing ethical systems. You are watching as a runaway trolley barrels down the railway tracks toward five people who cannot get out of the way. To prevent their deaths, your only option is to divert the trolley onto a sidetrack - but diverting would cause the death of one person on the sidetrack; clearly, the situation is very complicated based upon the environment the trolley exists in. To make a specific point, each of the simulations below drastically simplifies the ethical system that they represent and discounts the degree of complexity they all have been developed through.

\section{Deontological ethical system}

In a rule based ethical system the adjudicative and predictive aspects are the same. As applied to the trolley simulation the rule that would apply is that an agent may not kill another agent. Applying the trolley simulation to a deontological system, you would do nothing; you have two choices, change the direction of the Trolley or not. If you were to follow the deontological ethical system you would do nothing and allow the trolley to kill the five people who are unable to get out of the way.

\section{Consequential ethical system}

In a consequentialist ethical system we cannot predict our actions by reference to existing rules, but by consideration of the consequences of those actions. In the trolley simulation we can predict two consequences: one person dies or five people die. We are left with the conclusion that in order to save five persons we must act in a way that brings about the death of another person; this is so even though we may have deep moral revulsion toward such a predictive act. Indeed, McNaughten and Rawling have argued that pure consequentialist ethics is agent neutral; the moral compass of the actor cannot be taken into account in the determination of the best result of our actions [18].

\section{Virtue ethics system}

The primary focus of virtue ethics is the character of the actor, not the system of rules (deontology) or the consequences of the act (consequentialist). An act is good if it emphasizes an internal character trait considered to be admirable, generally based upon human wellbeing, reason, or care. In order for our actions and utterances to be good they must be in accordance with what a virtuous agent would do; neither rules nor the consequences of our acts are important. It is difficult to imagine a predictive scenario that could be made from virtue ethics, given that both the single person and the group of five persons are worthy of consideration. Perhaps it would serve the virtue of reason if the virtue ethics model predicted that it would be more reasonable to sacrifice the life of one person rather than five. The virtue of care must be considered in the choice to sacrifice one person's life for the lives of five; it would be nearly impossible to chose between the single person and five persons if a decision based upon virtue is strictly concerned with the wellbeing of all six people.

\section{Neo-pragmatism}

Understanding Neo-Pragmatism involves acknowledging the fact that we live in a contingent world. The factors that go into predicting our actions tomorrow may very well change 
tomorrow; indeed it is highly probable that some of those factors will change. The second factor that distinguishes Neo-Pragmatism from other ethical systems is that it is value based and no value is particularly privileged or particularly non-contingent. In other words, our values may differ from person to person and culture to culture and may also change from time to time. Applied to our predictive actions or statements the most we can do is justify our actions to ourselves and to others based upon the values that we hold at that particular time and under the particular contingent circumstances that may exist or which we believe will exist.

Applying Neo-Pragmatism to the trolley simulation we may say that we value female lives over male lives if it so happens that the five persons are male and the one person is female; we can decide to spare the one and sacrifice the five based on a value judgment of gender. Another scenario is that the one person is in a state of health, and the five are all terminally ill. Based on this consideration, should we then sacrifice the five for the one?

\section{Neo-pragmatism as an anticipatory system}

An Anticipatory System is a natural system that contains an internal predictive model of itself and of its environment, which allows it to change state in an instant in accord with the model's predictions pertaining to a later instant [16].

Applying Neo-Pragmatism to Rosen's definition of an Anticipatory System we can see that it fits very well. An ethical system is a model of how we adjudicate our past utterances and actions or how we can predict our future utterances and actions. It is clear that a particular ethical system does not need to be able to adjudicate our past conduct and predict our future conduct and indeed what we can learn from a Deontological System is that our predictive conduct often does not comport with the adjudication of our past conduct. Neo-Pragmatism is based upon an ever-changing environment interacting with our values - not our rules, but our values. Neo-Pragmatism does not place any particular value as privileged and so the greatest good - as argued by consequentialist ethics - is not necessarily the value that will be applied in a particular circumstance, nor will any particular virtue.

\section{Conclusion}

Masini said "these different visions of a desirable future are in some way embedded in the social structures from which they emerge, and are linked to the needs and the hopes of the people living at the time" [17: 1159]. This statement is remarkably contextual and anticipatory. Being embedded in a social structure a desirable future can be anticipated in much the same way as a deciduous tree anticipates the future coming of winter by dropping its leaves and conserving its lifeblood during the cold that will soon come. The future is also remarkable in its contingency upon the specific social structure from which it emerges and linked to those needs and hopes.

Hume posed the ethical question that has yet to be answered in a satisfactory manner: the "is-ought" problem, also known as Hume's guillotine. How is it that a statement of "what is" becomes a statement of "what ought to be?" I believe that Rorty and Rosen would re-describe the question in pragmatic terms as the difference between what was and what will be. As a system of ethics the predictive aspect of NeoPragmatism most closely models Rosen's Anticipatory System theory and can be a useful tool for systems thinkers, sociologists, ethicists and all persons interested in the study of the future and anticipation. The question of "what ought we to do now" must be addressed by Futures

Studies and the method by which we decide the "what" is of critical importance to life on this earth and the flourishing of human society.

Open Access This article is distributed under the terms of the Creative Commons Attribution 4.0 International License (http:// creativecommons.org/licenses/by/4.0/), which permits unrestricted use, distribution, and reproduction in any medium, provided you give appropriate credit to the original author(s) and the source, provide a link to the Creative Commons license, and indicate if changes were made.

\section{References}

1. Bell W (2004) Foundations of futures studies. New Brunswick, values, objectivity, and the good society. Transaction

2. Brandom RB (2000) Rorty and his critics. Blackwell, Oxford

3. Chu D, Ho WK (2006) A category theoretical argument against the possibility of artificial life: Robert Rosen's central proof revisited. Artificial Life 12(1):117-134

4. Chu D, Ho WK (2007) The localization hypothesis and machines. Artificial Life 13(3):299-302

5. Crisp R (2010) Virtue ethics and virtue epistemology. Metaphilosophy 41(1-2):22-40

6. Davis P, Pyper N (2015) Applying actor network theory and pragmatist thinking to the process of implementing scenarios. Int. J of Foresight and Innovation Policy 10(2-4):88-102

7. Di Beradino MA (2014) A dialogue on relativism: Rorty and Feyerabend. Contemporary Pragmatism 11(1):57-68

8. Dickstein M (ed) (1998) The revival of pragmatism: new essays on social thought, law and culture. Duke University Press, Durham

9. Edmonds B (2007) The practical modeling of context-dependent causal processes: a recasting of Robert Rosen's thought. Chemistry and Biodiversity: Special Issue on Robert Rosen 4(1):2386-2395

10. Folbre N, Wolf D (2013) The intergenerational welfare state. Population and Development Review 38(Suppl 1):36-51

11. Hickman L, Alexander T (eds) (1999) The essential Dewey (Vol 1 and 2). Indiana University Press, Bloomington

12. Hursthouse R (2013) Virtue ethics. In: Zalta EN (ed) the Stanford encyclopedia of philosophy. https://plato.stanford.edu/entries/ ethics-virtue/. Accessed 02 Aug 2017 
13. Hume D (2017) Treatise of human nature, book III, part I. Create Space Independent Publishing, Section I

14. James W (1975) Pragmatism: a new name for some old ways of thinking. Harvard University Press, Cambridge

15. Louie AH (2007) A living system must have noncomputable models. Artificial Life 13(3):299-302

16. Louie AH (2010) Robert Rosen's anticipatory systems. Foresight 12:18-29

17. Masini E (2006) Rethinking futures studies. Futures 38(10):11581168

18. McNaughton D, Rawling P (1991) Agent-relativity and the doing-happening distinction. Philosophical Studies 63:167185

19. Mead GH (1934) Mind, self and society. University of Chicago Press, Chicago

20. Miller CB (2002) Rorty and moral relativism. European Journal of Philosophy 10(3):354-374

21. Pierce C S $(1992,1999)$ The essential Peirce. Selected philosophical writings (vol 1 and 2). Indiana University press, Bloomington
22. Rorty R (1980) Pragmatism, relativism, and irrationalism. Proceedings and addresses of the American Philosophical Association 53(6):717-738. doi:10.2307/3131427

23. Rorty R (1989) Contingency, irony, and solidarity. Cambridge University Press, Cambridge

24. Rorty R (1991) Objectivity relativism and truth. Cambridge University Press, Cambridge

25. Rosen R (1991) Life itself: a comprehensive inquiry into the nature origin and fabrication of life. Columbia University Press, New York

26. Rosen R (2012) Anticipatory systems: philosophical, mathematical, and methodological foundations. Springer, New York

27. Swan RH (2010) Feedforward as an essential active principle of engagement in computer games. In: van Eck R (ed) Gaming and cognition: theories and practice from the learning sciences. Information Science Reference, Hershey, pp 108-136

28. Waelbers and Dorstewitz (2014) Ethics in actor networks, or: what Latour could learn from Darwin and Dewey. Sci Eng Ethics 20(1): 23-40. doi:10.1007/s11948-012-9408-1

29. Wells AJ (2006) In defense of mechanism. Ecological Psychology 18(1):39-65. doi:10.1207/s15326969eco1801 2 